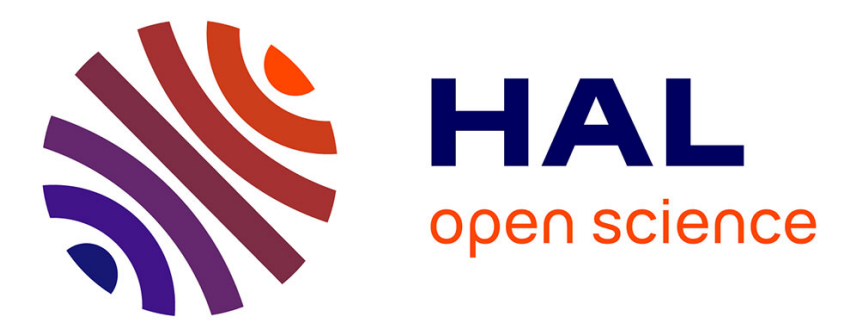

\title{
A systematic replacement strategy in the context of a strongly censored lifetime. Application to road markings
}

Maxime Redondin, Laurent Bouillaut, Dimitri Daucher, Nadège Faul

\section{To cite this version:}

Maxime Redondin, Laurent Bouillaut, Dimitri Daucher, Nadège Faul. A systematic replacement strategy in the context of a strongly censored lifetime. Application to road markings. ESREL 2019 29th European Safety and Reliability Conference, Sep 2019, Hanovre, Germany. 8p. hal-02967738

\section{HAL Id: hal-02967738 \\ https://hal.science/hal-02967738}

Submitted on 3 Nov 2020

HAL is a multi-disciplinary open access archive for the deposit and dissemination of scientific research documents, whether they are published or not. The documents may come from teaching and research institutions in France or abroad, or from public or private research centers.
L'archive ouverte pluridisciplinaire HAL, est destinée au dépôt et à la diffusion de documents scientifiques de niveau recherche, publiés ou non, émanant des établissements d'enseignement et de recherche français ou étrangers, des laboratoires publics ou privés. 
A systematic replacement strategy in the context of a strongly censored lifetime. Application to road markings.

\author{
Maxime Redondin \\ VEDECOM Institut, 23 bis Allée des Maronniers, F-78000 Versailles, France. \\ E-mail: maxime.redondin@vedecom.fr \\ Laurent Bouillaut \\ Université Paris-Est, Grettia (IFSTTAR), F-7755 Marne-la-vallée, France. E-mail: laurent.bouillaut@ifsttar.fr \\ Dimitri Daucher \\ Université Paris-Est, Lepsis (IFSTTAR), F-7755 Marne-la-vallée, France. E-mail: dimitri.daucher@ifsttar.fr
}

Nadège Faul

VEDECOM Institut, 23 bis Allée des Maronniers, F-78000 Versailles, France.

E-mail:nadege.faul@vedecom.fr

The quality and reliability of road infrastructure and its equipment play a major role in road safety. This is especially true if we are interested in autonomous vehicle traffic. Markings line are detected by camera. This option needs an accurate maintenance strategy. In that way, their retroreflection luminance is measured for evaluating their degradation. A line is replaced according to the yearly inspection. The consensus strategy is to define a degradation models of markings based on a regression method. Such models provide a prediction of failure occurrences and a preventive replacement is engaged before this instant. This paper proposes alternatively a systematic age-based replacement by strategic areas. In previous study, an Agglomerative Hierarchical Clustering identifies markings with the same degradation model. The feedback database is strongly censored because the exact failure time isn't observed. To deal with this drawback, an $\mathcal{W}$ EM Algoritm was proposed to determine a Weibull model. For each strategic area, a cost function can therefore be defined according to both maintenance costs and the associated Weibull model. The optimum replacement period was finally defined as the minimum point of the cost function. The French National Road 4 (NR4) brocken centerline illustrates this approach. Segmented into five clusters, each one admits its own optimum replacement step. The proposed replacement strategy is generic its application is not limited to our case study

Keywords: Road marking, Retroreflection luminance, Preventive maintenance, EM Algorithm, Age-based replacement, censored lifetime.

\section{Introduction}

The quality and reliability of road infrastructure and its equipment play a major role in road safety. This is especially true for autonomous vehicule traffic. Currently, autonomous vehicles are guided by several sensors. In particularly, one option is to equip the vehicle with a camera able to detect lanes defined by road markings (Hillel et al. (2014)). The lane detector proposed by VEDECOM is based on a mutli-agent approach able to detect in average $95 \%$ of road markings for only $4 \%$ of false alarm (Revilloud et al. (2013)). However, applied on a deteriorate road infrastructure : the emergency line is $85 \%$ detected and the broken center line is not detected (Revilloud et al. (2016)). This solution requires a maintenance strategy guaranteeing that road markings remain perceptible to a human eye or an autonomous vehicle camera.

According to both the NF EN 1436 rules (AFNOR (2018)) and the available inspection devices, the retroreflection luminance of markings is the only measure used for evaluating marking degradation. A retroreflective marking reflects light from a vehicle headlight back in the direction of the driver. In the case of a waterborne marking, the retroreflective property is guaranteed by glass bead mixed into the paint during application (Babic et al. (2015))

The retroreflection luminance is measured in millicandela per square meter and per lux $\left(\mathrm{mcd} / \mathrm{m}^{2} / \mathrm{lx}\right.$ ). This measure corresponds to the night-time visibility. For white waterborne mark-

Proceedings of the 29th European Safety and Reliability Conference.

Edited by Michael Beer and Enrico Zio

Copyright (C) 2019 by ESREL2019 Organizers. Published by Research Publishing, Singapore

ISBN: 981-973-0000-00-0 :: doi: 10.3850/981-973-0000-00-0_esrel2019-paper 
ings, the standard degradation model is presented by the figure 1 . A new marking admits a strong retroreflection luminance $\left(600 \mathrm{mcd} / \mathrm{m}^{2} / \mathrm{lx}\right.$ for example) and is seen as a white visible object. The retroreflection luminance decreases over the time and the marking loses paint and glass bead. In the worst case, the marking admits a low retroreflection luminance $\left(50 \mathrm{mcd} / \mathrm{m}^{2} / \mathrm{l} x\right.$ for example) and is seen as a dark grey no-visible object.

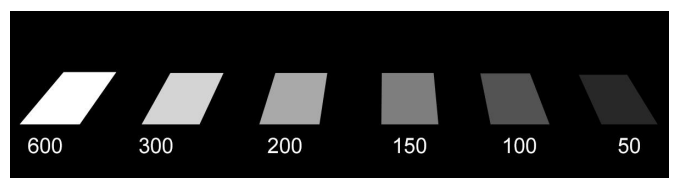

Fig. 1. Night-time visibility of markings according to the retroreflection luminance (Féré (2016)

A markings line is a no-repairable system and should be replace. In France, a minimum threshold of $150 \mathrm{mcd} / \mathrm{m}^{2} / \mathrm{lx}$ is required for a new marking (AFNOR (2018)). In this paper, this threshold is interpreted as the maximum degradation level. Currently, lines are periodically inspected by a dynamic retroreflectometer. The figure 2 presents an Ecodyn-3 developed by MLPC. The device is fixed on one of a vehicule side (Fig 2,(a)). Ecodyn give off a white light on the marking and measures the quantity of light retroreflected (Fig 2,(b)). The measuring step is $40 \mathrm{~cm}$ but only one average measure over $100 \mathrm{~m}$ is saved. This process rejects the retroreflection luminance of the pavement. For safety reason, replacement campaigns are defined according to a strategic area. The consensus preventive replacement strategy is to define a degradation model of markings based on a regression method.
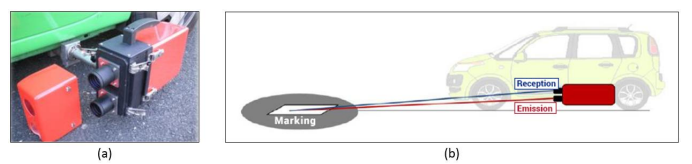

Fig. 2. Presentation of an Ecodyn-3 : (a) the device ; (b) the measuring process

The retroreflection luminance is explained by different variables. For example, $\mathrm{Lu}$ (1995) proposed an exponential model as a function of age of markings, Abboud and Bowman (2002) developed different exponential models as a function of the Annual Average Daily Traffic (AADT) and the age of markings, Sitzabee et al. (2009) proposed a multilinear model as a function of time, the initial retroreflection, the AADT, the lateral locations of markings and marking color. Such models provide a prediction of failure occurrences and a pre- ventive replacement is engaged before this instant. However, these models present some difficult to be apply directly to a given road network. For example, a road is not systematically maintained in its entirety. For safety reasons, road managers maintain only specific areas at a time. This is especially true for the pavement.

In this indistrual context, a maintenance model based on the reliability theory represents an original alternative approach. These models are generally associated to an inspection strategy. In the case of a periodic inspection, three preventive strategies are identified (Rausand and Hoyland (2004)). A systematic approach consists to define an optimum maintenance step according to maintenance costs and a lifetime model(Park (1988a Park (1988b)). A conditional approach consists to define an optimum preventive degradation threshold according to maintenance costs, a given maximum degradation threshold and a degradation model (Grall et al. (2002)). A predictive approach is similar to a conditional model excepted that the preventive threshold is replaced by a failure risk as the Remaining Useful Life.

This paper proposes a first alternative based on a systematic age based replacement by strategic areas. This choice is according to previous studies. One given markings line is segmented by an Agglomerative Hierarchical Clustering (AHC) according to past inspections (Redondin et al. (2017)). Each cluster was interpreted with respect to a specific area of the road network and admits its own retroreflective luminance evolution over time. This fact leads to interpret each cluster as a maintenance strategic areas (Redondin (2018)). Currently, road markings are monthly or yearly inspected by a retroreflectometer. Thus, a periodical approach isn't able to determine the exact failure time for any marking. In fact, this moment is systematically censored. According to one given cluster, an $\mathcal{W}$ EM algorithm estimates this censored lifetime and deduces a Weibull analysis (Redondin et al. (2018)). Finally, each cluster was defined as a strategic maintenance area associated to one Weibull model.

The replacement strategy is associated to a cost function. This one is defined both by the replacement cost and the Weibull model. The optimum replacement step is finally defined as the minimum point of the cost function. For each strategic area, this function evaluated also the benefice of this preventive approach over a corrective approach.

The French National Road 4 (NR4) brocken center line illustrates this approach. Segmented into five clusters, each one admits it own optimum replacement step. As the proposed replacement strategy is generic its application is obviously not limited to our road marking case study. 


\section{Systematic preventive replacement by strategic area}

In this paper, $C$ is supposed be a clear-defined replacement strategic area of a given markings line. This section is composed by $\# C=n>0$ Points of Reference (PR) and $M \geqslant 1$ life cycles. Each PR is interpreted as one specific marking to simply. The retroreflection luminance of the marking $i$ at the inspection $t>0$ is $R L_{t}(i)$. The age of a marking is defined the time between the last replacement and the current inspection $t>0$. The section $C$ could be defined by a clustering approach of the feedback database (Redondin et al. (2017)).

\subsection{Reference Weibull distribution}

The age based replacement is depended to a lifetime model adapted to $C$. Standard lifetime models of markings are based on a Weibull distribution (Redondin et al. (2018); Sathyanarayanan et al. (2008)).

According to the feedback database, the proposed $\mathcal{W}$ EM algorithm identified three censored lifetimes (Redondin et al. (2018)). If a failure has occurred before the first inspection, then it is called left-censored. If a failure has occurred between two inspections, then it is called intervalcensored. If a failure hasn't been observed, then it is called right-censored. According to a given life cycle, all censored lifetime are estimated by the algorithm. The Weibull distribution is parametered according to estimated lifetime and a Maximum Likelihood Estimator optimized by a fixed point approach (Redondin et al. (2018)).

The whole censored lifetime observed on the whole life cycle is $\mathfrak{C}$. The observed lifetime of the marking $i \in \llbracket 1 ; n \rrbracket$ over the cycle $m \in \llbracket 1 ; M \rrbracket$ is $t_{i}^{m}$. The censorship indicator is $\delta_{t_{i}^{m}}$. If the lifetime is left, interval or right-censored, then $\delta_{t_{i}^{m}}=1,2,3$ respectively.

$\mathfrak{C}=\left\{\left(t_{i}^{m}, \delta_{t_{i}^{m}}\right) / i \in \llbracket 1 ; \# C \rrbracket ; m \in \llbracket 1 ; M \rrbracket\right\}$

The Weibull model adapted to $C$ is estimated by the $\mathcal{W} E M$ algorithm trained on $\mathfrak{C}$. This distribution is $\mathcal{W}(\alpha, \beta)$.

\subsection{Preventive age based replacement}

The replacement area $C$ is associated to the Weibull distribution $\mathcal{W}(\alpha, \beta)$. Figure 3 presents the replacement strategy. The whole $C$ is systematicly replaced every $T^{*}$ time unit. The preventive replacement cost is $c_{\text {pre }}$. If a global failure is observed between two replacement campaigns, then $C$ is replaced. An additional corrective cost defined by $c_{c o r}=r \times c_{p r e}$ is engaged. The maintenance schedule is also reset after a corrective

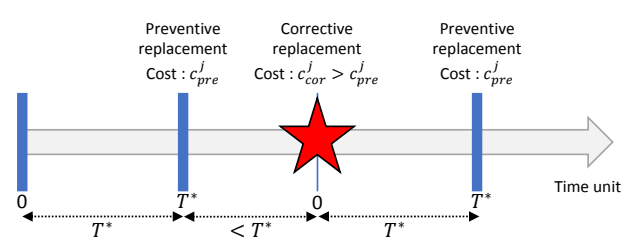

Fig. 3. Age based replacement.

action. The optimum replacement step $T^{*}$ is a compromise between the risk to realize an overmaintenance and the risk to observe a generalized failure.

$$
\begin{aligned}
C(t) & =\frac{c_{\text {pre }}+c_{\text {cor }} F(t)}{\int_{0}^{t} R(x) d x} \\
& =\frac{c_{\text {pre }}+\left(r \times c_{\text {pre }}\right)\left(1-e^{-(t / \alpha)^{\beta}}\right)}{\int_{0}^{t} e^{-(x / \alpha)^{\beta}} d x} \\
& =c_{\text {pre }} \times \frac{1+r\left(1-e^{-(t / \alpha)^{\beta}}\right)}{\int_{0}^{t} e^{-(x / \alpha)^{\beta}} d x}
\end{aligned}
$$

A replacement is supposed to be perfect. Markings composing $C$ back to the situation "As Good As New" (AGAN). The renew theorem identify the fonction (2) as the mean maintenance cost by time unite over an infinite horizon (Rausand and Hoyland (2004)). $F$ and $R$ are respectively the cumulative and the reliability functions associated to $\mathcal{W}(\alpha, \beta)$. Finally, the optimum replacement step is the minimum of $C(t)$ :

$$
T^{*}=\left\{\tau / C(\tau)=\min _{t>0} C(t)\right\}
$$

The asymptotic cost represents also the mean cost by time unite according to an exclusive corrective replacement strategy. This cost is done by the function (4) which depends to the Mean Time Before Replacement $(M T B R)$ associated to $\mathcal{W}(\alpha, \beta)$. $M T B R=\alpha \Gamma(1+1 / \beta)$ with the gamma function $\Gamma(x)=\int_{0}^{+\infty} t^{x-1} e^{-t} d t$ (in the case of a Weibull distribution).

$$
\begin{aligned}
C(\infty) & =\lim _{t \rightarrow+\infty} C(t) \\
& =\frac{c_{p r e}+c_{c o r}}{\int_{0}^{+\infty} R(x) d x} \\
& =\frac{c_{\text {pre }}+r \times c_{\text {pre }}}{M T B R} \\
& =\frac{c_{\text {pre }} \times(1+r)}{\alpha \Gamma(1+1 / \beta)}
\end{aligned}
$$




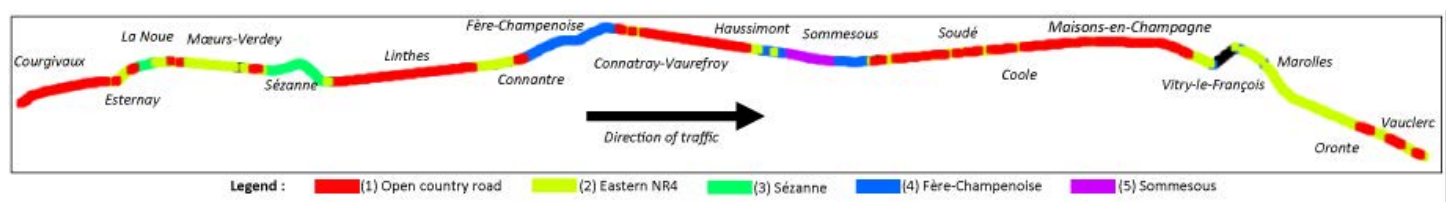

Fig. 4. The NR4 broken center line segmented into 5 replacement areas

$r=c_{c o r} / c_{\text {pre }}>1$ is the financial corrective penalty. The ratio between the preventive and the corrective strategy is $C(t) / C(\infty)$. Consequently, the function (5) represent the economic benefice realized by the systematic strategy. Three cases are identified.

- If $1-C(t) / C(\infty)<0$, then the corrective replacement is economically more interesting at $t$.

- If $1-C(t) / C(\infty)>0$, then the preventive replacement is economically more interesting at $t$.

- If $1-C(t) / C(\infty)=0$, then the preventive replacement is the corrective replacement.

The minimum of (5) is also done to $t=T^{*}$. The benefice of a preventive replacement done at $t$ over the corrective replacement is estimated by $1-C(t) / C(\infty)$.

$$
\begin{aligned}
& 1-\frac{C(t)}{C(\infty)}= \\
& 1-\frac{1+r\left(1-e^{-(t / \alpha)^{\beta}}\right)}{\int_{0}^{t} e^{-(x / \alpha)^{\beta}} \mathrm{d} x} \times \frac{\alpha \Gamma(1+1 / \beta)}{1+r}
\end{aligned}
$$

\section{Application to French NR4}

\subsection{Presentation of the French NR4}

The broken centerline of the French National Road 4 (NR4) is considered to illustrate the proposed approach. The NR4 runs between Paris and Strasbourg. Since 2007, the section of this road between Courgivaux and Vauclerc $(\sim 102 \mathrm{~km})$ has been managed by the DIR Est, which inspects this section of the road once a year.

Inspections are organized in September in collaboration with CEREMA Est. The selected retroreflectometer is an Ecodyn. Replacement actions are realized in March according to both the inspection report and the maintenance budget.

An Agglomerative Hierarchical Clustering (AHC) segmented the feedback database into 5 clusters (Redondin (2018)). Each one is interpreted as a replacement strategic area :

- The cluster 1 corresponds to open country roads

- The cluster 2 corresponds to the region of Vitry-le-Francois.

- The cluster 3 corresponds to the bypass of Sezanne
- The cluster 4 corresponds to the bypass of Fere-Champenoise

- The cluster 5 corresponds to a local highway near of Sommesous.

The NR4 is a diversified road infrastructure. The clustering process identifies the five most representatives. Each one admits it own lifetime model.

\subsection{Reference Weibull model by replacement area}

Each cluster is associated on Weibull model estimated by the proposed $\mathcal{W}$ EM Algorithm (Redondin et al. (2018)). This section presents the case of the NR4 cluster 1 . It is the larger cluster ( $43 \%$ of the road) and represents here the brocken center line for this reason. The cluster 1 presents 23 life cycles between 2007 and 2016 and also 1315 censored lifetime. According to a maximum degradation thresholds of $150 \mathrm{mcd} / \mathrm{m}^{2} / \mathrm{lx}$, the $\mathcal{W}$ EM algorithm proposed the Weibull distribution $\mathcal{W}(22.14 ; 1.82)$.

Table 1. Weibull analysis of the NR4 cluster 1 $\mathcal{W}(22.14 ; 1.82)$.

\begin{tabular}{|c|c|c|}
\hline $\begin{array}{c}\text { Observed } \\
\text { failure } \\
\text { (months) }\end{array}$ & $\begin{array}{c}\text { Numbers } \\
\text { (frequency) }\end{array}$ & $\begin{array}{c}\text { Estimated } \\
\text { failure } \\
\text { (months) }\end{array}$ \\
\hline $\mathbf{( 6 , 1 )}$ & $261(20 \%)$ & 4 \\
\hline $\mathbf{( 6 , 3 )}$ & $56(4 \%)$ & 21 \\
\hline $\mathbf{( 1 8 , 2 )}$ & $278(21 \%)$ & 12 \\
\hline $\mathbf{( 1 8 , 3 )}$ & $355(27 \%)$ & 28 \\
\hline $\mathbf{( 3 0 , 2 )}$ & $248(19 \%)$ & 23 \\
\hline $\mathbf{( 3 0 , 3 )}$ & $18(1 \%)$ & 38 \\
\hline $\mathbf{( 4 2 , 2 )}$ & $73(6 \%)$ & 35 \\
\hline $\mathbf{( 4 2 , 3 )}$ & $25(2 \%)$ & 48 \\
\hline $\mathbf{( 5 4 , 2 )}$ & $1(0 \%)$ & 46 \\
\hline
\end{tabular}

The table 1 presents the associated Weibull analysis. The first column lists censored failures observed by an inspection campaign. Failures are noted according to the formalism introduced by $\mathfrak{C}(1)$. The second precises the number of failure observed. The last presents the failure moment estimated by the $\mathcal{W}$ EM algorithm. For example, during the first inspection (6 months), $20 \%$ of markings are failed and left censored. The $\mathcal{W}$ EM algorithm estimates the failure moment at 4 months.

All censored cases are presented. Failures right censored represent the main case $(35 \%)$. Censures are observed at 6,18 and 30 months. The $\mathcal{W}$ EM algorithm estimated respectively to 21,28 and 38 months. According to the table, a naive replacement step is 28 months (91\% of cumulative 
failure). However, this estimation doesn't take into account the economic cost of this strategy.

\subsection{Age based replacement strategy}

Table 2. NR4 systematic replacement strategy.

\begin{tabular}{|c|c|c|}
\hline $\begin{array}{c}\text { Cluster } \\
\text { Numbers (Frequency) } \\
\mathcal{W}(\alpha ; \beta) \\
M T B R\end{array}$ & $\begin{array}{c}\text { Optimum } \\
\text { replacement } \\
\text { step } T^{*} \\
- \\
1-\frac{C\left(T^{*}\right)}{C(\infty)}\end{array}$ & $\begin{array}{c}\text { Preventive } \\
\text { cost } \\
- \\
\text { Cost by } \\
\text { unit time }\end{array}$ \\
\hline $\begin{array}{c}1 \\
420(43 \%) \\
\mathcal{W}(22.14 ; 1.82) \\
20\end{array}$ & $\begin{array}{c}14 \\
- \\
16 \%\end{array}$ & $\begin{array}{c}4339 \\
- \\
738\end{array}$ \\
\hline $\begin{array}{c}2 \\
336(35 \%) \\
\mathcal{W}(17.17 ; 1.39) \\
16\end{array}$ & $\begin{array}{c}18 \\
- \\
4 \%\end{array}$ & $\begin{array}{c}3471 \\
- \\
852\end{array}$ \\
\hline $\begin{array}{c}3 \\
63(7 \%) \\
\mathcal{W}(18.60 ; 1.47) \\
17\end{array}$ & $\begin{array}{c}16 \\
- \\
6 \%\end{array}$ & $\begin{array}{c}651 \\
- \\
145\end{array}$ \\
\hline $\begin{array}{c}4 \\
112(12 \%) \\
\mathcal{W}(23.63 ; 2.62) \\
21\end{array}$ & $\begin{array}{c}13 \\
- \\
33 \%\end{array}$ & $\begin{array}{c}1157 \\
- \\
147\end{array}$ \\
\hline $\begin{array}{c}5 \\
37(4 \%) \\
\mathcal{W}(31.76 ; 2.73) \\
28\end{array}$ & $\begin{array}{c}18 \\
- \\
35 \%\end{array}$ & $\begin{array}{c}382 \\
- \\
35\end{array}$ \\
\hline $\begin{array}{c}\text { Global } \\
968(100 \%) \\
\mathcal{W}(21.44 ; 1.70) \\
20\end{array}$ & $\begin{array}{c}15 \\
- \\
13 \%\end{array}$ & $\begin{array}{c}10000 \\
- \\
1822\end{array}$ \\
\hline
\end{tabular}

The table 2 presents the age based replacement strategy adapted to the NR4 brocken center line. The four input parameters considered are :

- The maximum degradation thresholds for each cluster is $L=150 \mathrm{mcd} / \mathrm{m}^{2} / \mathrm{lx}$.

- The global maintenance preventive budget is $B=10000$.

- The maintenance budget is divided evenly between clusters.

- The financial penalty is order $r=3$.

The table 2 is divided into three columns : the considered cluster, the preventive strategy and the financial budget. Each cluster is described by the number (and frequency) of markings, the associated Weibull distribution and the associated $M T B R$. The strategy is summarized to the optimum step $T^{*}$ associated to the economical benefice calculated by the function (4). The financial budget is defined by the preventive cost and the cost by unit time.
For example, the cluster 1 is composed by 420 markings (43\% of the road). The associated Weibull distribution is $\mathcal{W}(22.14 ; 1.82)$. The $M T B R$ is 20 months and the recommended replacement step is 14 months. The preventive cost is 4339 and the cost by months is estimated to 738 . This preventive approach predicts an economy of $16 \%$ over a corrective approach.

The figure 5 presents the associated cost function (4). A preventive replacement is economically not interesting before the 6th month. This approach is more adequate between and 6 and 35 months. The minimum (and optimum replacement step) is 14 months. After the 35th months, preventive and corrective strategies are similar.

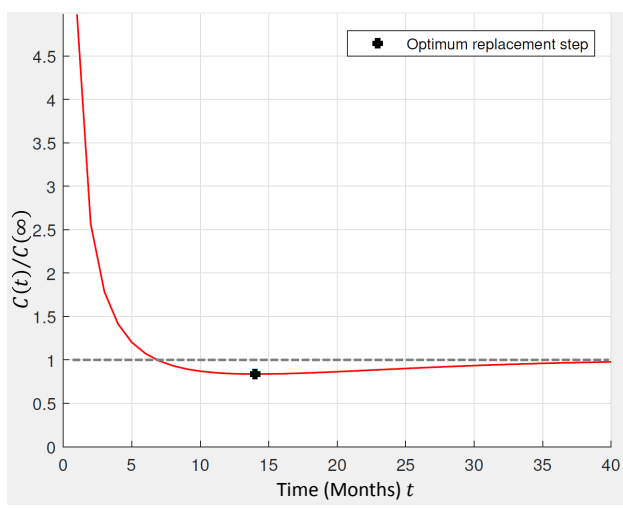

Fig. 5. Cost function associated to the cluster 1

Each cluster admits it own replacement step : $14,18,16,13$ and 18 months. However, the economic benefice of this preventive strategy over a full corrective strategy is inequality from one cluster to another : the cluster 2 presents only $4 \%$ for example. In fact, the benefice is correlated to the shape parameter $\beta$ of the Weibull distrubtion associated to the cluster : the larger $\beta$, the more interesting the benefit.

The last cluster of table 2 considers the whole brocken center line. This case is a theoretical strategy because it couldn't be logistically realized. The theoretical replacement step is 15 months for a benefice of $13 \%$. However, the mean replacement step is 15.8 months for a mean benefice of $18.8 \%$. Finally, the preventive replacement by strategic area is credible, proposes a similar replacement step and predicts a more interesting benefice.

The mean difference between the $M T B R$ and the replacement step is 5.8 months. This difference coincides to the time between one inspection (September) and one replacement campaign (March).

The proposed systematic replacement strategy presents several advantages : a markings line seg- 
mented into different replacement strategy, each one is associated to one specific Weibull analysis and finally one proposed optimum replacement step according both to the maintenance budget and the considered maximum degradation threshold. However, the strategy doesn't take into account the current management of the NR4. For example, if the replacement campaign is fixed during the winter, then the campaign will be canceled for logistic reasons.

\subsection{Sensibility tests}

The proposed preventive replacement strategy depends mainly of two parameters : the maximum degradation threshold $L$ and the financial penalty cost $r$. Applied to the NR4 cluster 1, this section presents sensibility tests to these parameters. The proposed approach consist to determine different replacement step according to $L$ or $r$. A regression is realized to deduce a predictive model.

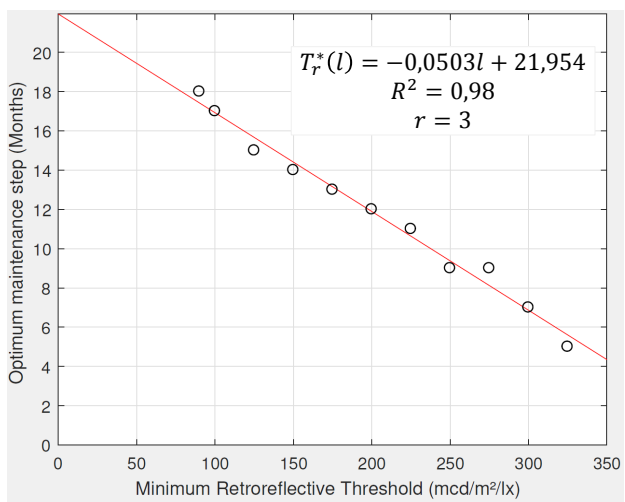

Fig. 6. Replacement step associated to the NR4 cluster 1 according to the maximum degradation thresholds

The figure 6 presents the sensibility to the choice of the maximum degradation threshold $L$. According to the previous section, the financial penalty cost is $r=3$. The replacement step is predicted by a linear model as function of $L$. The criterion of determination is 0.98 : this model admits a good prediction level. Not surprisingly, the replacement step decreases over $L$. If $L=0$, then the optimum step is 22 months. If $L$ increases of $20 \mathrm{mcd} / \mathrm{m}^{2} / \mathrm{lx}$, then the replacement step shifts 1 month earlier.

The figure 7 presents the sensibility to the choice of the financial penalty $r$. According to the previous section, the maximum degradation threshold is $L=150 \mathrm{mcd} / \mathrm{m}^{2} / \mathrm{lx}$. The replacement step is predicted by a logarithmic model as function of $r$. The criterion of determination is 0.96 : this model admits a good prediction level. Not surprisingly, the replacement step decreases

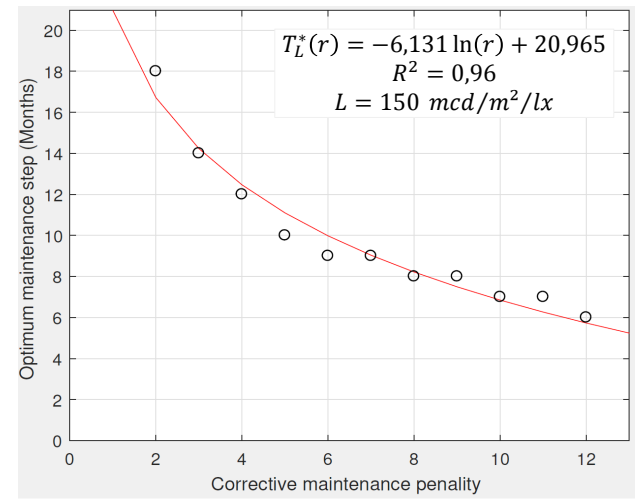

Fig. 7. Replacement step associated to the NR4 cluster 1 according to the financial penalty cost

over $r$. If $r=1$, then the optimum step is 21 months. If $r>3$, then the decrease process is slower. More precisely : if $r \in[1,3]$, then increase $r$ of one unit is equivalent to shift to 2.6 month earlier the replacement step in average and if $r>3$, then increase $r$ of one unit is equivalent to shift to 0.5 month earlier the replacement step in average. However, the replacement step is stationary in three situations $: r \in[6,7],[8,9]$ and $[10,11]$.

The sensibility to the maximum degradation threshold $L$ and the financial penalty cost $r$ is modeling by a regression method. These functions could compare different systematic replacement strategies. However, each cluster seems to be associated to one optimum regression method. The sensibility into $L$ of the NR 4 cluster 5 is predicted by an exponential regression (Redondin (2018)) for example.

\section{Conclusion}

The proposed systematic age based replacement approach by strategic area is a credible preventive strategy. It bases into three main points : the markings line is defined replacement areas, each one is associated to lifetime model based on a Weibull distribution and a replacement step is deduced.

The NR4 brocken center line illustrates this approach. Previous studies shows that a clustering approach segmented the line into five area. The given maximum degradation of the retroreflection luminance is $150 \mathrm{mcd} / \mathrm{m}^{2} / \mathrm{lx}$. Currently, the feedback database is censored. A EM solution is developed to associate one Weibull model for each area and to estimate censored lifetimes. However, the relative short lifetime of markings encourages to increase the frequency of inspection (every 6 months for example). The optimum replacement step by area is deduced by a cost function associated both to the Weibull model and the maintenance budget. For example, the NR4 cluster 1 
corresponds to open country roads. The preventive strategy proposes one replacement every 14 months (table 2).

Segmented the line into different areas is more interesting to consider the whole complete NR4 brocken center line. First, this last case is not logistically replaceable. Second, even if it was realizable, then replacement steps are similar The theoretical replacement step associated to the whole line 15 months and the mean replacement step by cluster is 15.8 months. Third, segmented the line into different areas allows a better benefice. The theoretical strategy predicts an economic benefice of $13 \%$ while the mean economic benefice by cluster is $18.8 \%$. However, the benefice is inequality from one cluster to another. For example, cluster 2 and 5 present respectively the less and the most interesting economic benefice : $4 \%$ and $35 \%$. This option is correlated to the associated Weibull model.

The proposed systematic strategy is mainly depended to two parameters : the maximum degradation thresholds and the financial penalty cost. Regression methods predict the optimum step according to these parameters. Associated functions present a solution to compare different strategy. However, the choice of the method seems to be depend to the cluster.

Finally, the proposed strategy correspond to a "passive" replacement of road markings. Each area is associated to one optimum replacement step and a cost by unit time is also evaluated to finance the next replacement. This last present two main problems. First, the optimum replacement step is independent to the current management of the considered road infrastructure. For example, if the next replacement campaign is planned during the winter, then it will be cancel. Second, after the creation of the maintenance model, this last is independent to inspection campaign. For example, the cost function (2) doesn't take into account the cost of one complete inspection. The strategy implies that the considered lifetime model is stable over the time and corrective actions will be engage thanks to an alarm. However, this approach is no-adapted to an autonomous vehicle traffic.

Two interrogations are identified. The Weibull model associated to markings is currently estimated by a EM algorithm. Still on a context of a strong censored lifetime, alternatives based on a bayesian approach is recently proposed (Ducros and Pamphile (2018) ; Marsili et al.(2018)); Park et al.(2018)). An alternative based on this solution is considered.

The systematic approach is a credible strategy to replace road markings. A first condition-based replacement by strategic area is also proposed by authors (Redondin (2018)). This credible alternative predicts a better economic benefice for a less common replacements. This approach avoids also the problem of winter maintenance. Unfortunately, the current model doesn't take into account the Weibull model associated to a given area and is optimum only during the first 24 months. Two other alternatives are considered : a predictive replacement based on the Remaining Useful Lifetime and a semi-markovian approach. A comparative study is necessary to determine the optimum strategy.

\section{Acknowledgment}

VEDECOM and IFSTTAR thank the DIR Est and the CEREMA for inspection data on the National Road 4.

\section{References}

Abboud, N. and B. Bowman (2002). Cost-and longevity-based scheduling of paint and thermoplastic striping. Transportation Research Record: Journal of the Transportation Research Board 1(1794), 55-62.

AFNOR (2018). Nf en 1436 (january 2018) maintenance - maintenance terminology.

Babic, D., T. Burghardt, and D. Babic (2015). Application and characteristics of waterborne road marking paint. International Journal for Traffic and Transport Engineering 5(2), 150169.

Ducros, F. and P. Pamphile (2018). Bayesian estimation of weibull mixture in heavily censored data setting. Reliability Engineering \& System Safety 180, 453-462.

Féré, F. (2016). Guide pratique de la signalisation horizontale. SIGNATURE GROUP.

Grall, A., L. Dieulle, C. Bérenguer, and M. Roussignol (2002). Continuous-time predictivemaintenance scheduling for a deteriorating system. IEEE transactions on reliability 51(2), 141-150.

Hillel, A., R. Lerner, D. Levi, and G. Raz (2014). Recent progress in road and lane detection: a survey. Machine Vision and Applications 25(3), 727-745.

Lu, J. (1995). Performance of Traffic Markings in cold regions. Transportation Research Center, University of Alaska Fairbanks, Report No. INE/TRC 95.03 (1995).

Marsili, F., J. Bödefeld, P. Croce, and F. Landi (2018). Bayesian approaches to lifetime prediction. In Safety and Reliability-Safe Societies in a Changing World, pp. 707-715. CRC Press.

Park, J., J. Lee, and S. Ahn (2018). Age replacement model using the parameter estimation of weibull distribution with censored lifetimes. In 2018 IEEE International Conference on Prognostics and Health Management (ICPHM), pp. 1-6. IEEE.

Park, K. (1988a). Optimal continuous-wear limit replacement under periodic inspections. IEEE Transactions on Reliability 37(1), 97-102. 
Park, K. (1988b). Optimal wear-limit replacement with wear-dependent failures. IEEE Transactions on Reliability 37(3), 293-294.

Rausand, M. and A. Hoyland (2004). System Reliability Theory-Models, Statistical Methods, and Applications. Wiley.

Redondin, M. (2018). Approches de classifications á partir de données fortement censurées pour lanalyse de fiabilité et la définition de stratégies de maintenance. Application aux marquages routiers dans un contexte de véhicules autonomes. Ph. D. thesis, Université de Paris-Est.

Redondin, M., L. Bouillaut, D. Daucher, and N. Faul (2017). Temporal clustering of retroreflective marking. In European Safety and Reliability Conference, Portorz, Slovenia, pp. 7p.

Redondin, M., L. Bouillaut, A. Same, D. Daucher, and N. Faul (2018). Alternative weibull analysis for road markings: an em approach. In European Safety and Reliability Conference, Trondheim, Norway, pp. 7p.

Revilloud, M., D. Gruyer, and E. Pollard (2013). An improved approach for robust road marking detection and tracking applied to multi-lane estimation. In Intelligent Vehicles Symposium (IV), 2013 IEEE, pp. 783-790. IEEE.

Revilloud, M., D. Gruyer, and M.-C. Rahal (2016). A new multi-agent approach for lane detection and tracking. In Robotics and Automation (ICRA), 2016 IEEE International Conference on, pp. 3147-3153. IEEE.

Sathyanarayanan, S., V. Shankar, and E. T. Donnell (2008). Pavement marking retroreflectivity inspection data : A weibull analysis. Journal of the Transportation Research Board. 2055, 6370.

Sitzabee, W., J. Hummer, and W. Rasdorf (2009). Pavement marking degredation modeling and analysis. Journal of infrastructure systems 15(3), 190-199. 